\title{
Recomendaciones de la Asociación Mexicana de Cirugía General A.C. De regreso a otra normalidad en cirugía
}

\author{
Back to another normality in surgery, Mexican \\ Surgical Association recomendations
}

\author{
Juan Roberto Torres Cisneros, ${ }^{*}$ Salvador Francisco Campos Campos ${ }^{\ddagger}$
}

* Presidente de la Asociación Mexicana de Cirugía General 2019-2020.

₹ Ex presidente de la Asociación Mexicana de Cirugía General.

Recibido: 15/06/2020 Aceptado: 07/07/2020

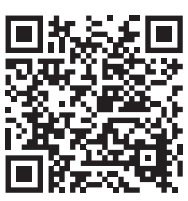

$\mathrm{L}$ a Asociación Mexicana de Cirugía General (AMCG), organización líder integrada por médicos especialistas en cirugía general, en cumplimiento de su objeto que es pugnar por una mejor preparación científica de sus asociados y velar por el ejercicio de la profesión y especialidad en un marco de seguridad para los pacientes y profesionales de la salud, con la información científica existente hasta el momento, se permite hacer las siguientes recomendaciones para la reanudación de los programas cirugía electiva:

\section{A. Consideraciones generales: COVID-19 y cirugía}

- Algunas patologías pueden someterse a tratamiento médico y no quirúrgico, sin que ello implique un riesgo para el paciente.

- El retraso en el tratamiento de algunas cirugías puede favorecer complicaciones en los pacientes y condicionar un mal resultado.

- Hay informes en la literatura internacional del desarrollo de complicaciones respiratorias en un porcentaje mayor que el habitual y un aumento en la morbimortalidad perioperatoria en pacientes quirúrgicos con infección por SARS-CoV-2 (COVID-19), ya sea conocida desde el preoperatorio o no conocida y desarrollada en el postoperatorio.

- La cirugía y la anestesia general de pacientes con infección por SARS-CoV-2 (COVID-19) son procedimientos de alto riesgo de contaminación del equipo quirúrgico involucrado. Especialmente durante el manejo de la vía aérea.

- Tener en cuenta la disponibilidad de recursos para la creación y mantenimiento de circuitos de traslado de pacientes y áreas no-COVID-19 para la realización de las intervenciones quirúrgicas.

- Es importante evaluar de forma continua las condiciones epidemiológicas de la población, donde se encuentra el área geográfica y el centro hospitalario, así se conocerá el riesgo de infección de pacientes y profesionales de la salud.

- Evitar o controlar en lo posible los procedimientos que generan aerosoles y salpicaduras y utilizar el equipo de protección individual correspondiente.

- Procurar el ingreso hospitalario en el mismo día de la cirugía. Limitar lo más posible el número de días de estancia hospitalaria.

- Restricción del número de visitantes y acompañantes al máximo durante la estancia hospitalaria.

- Estricto seguimiento de las recomendaciones de distanciamiento físico, higiene y uso de mascarillas por parte 
de pacientes, visitantes, acompañantes y profesionales durante el periodo de estancia hospitalaria.

- La vigilancia activa y separación de la circulación de cirugía electiva para el aislamiento de aquellos pacientes que desarrollen síntomas o signos compatibles con COVID-19.

\section{B. Con relación a la exclusión de pacientes con infección activa (COVID-19) previo a procedimientos quirúrgicos programados, recomendamos:}

- Generar y adecuar con la institución protocolos y procesos preoperatorios de exclusión de pacientes con infección activa de SARS-CoV-2.

- Efectuar una primera evaluación clínica y de antecedentes epidemiológicos con aproximadamente 14 días de antelación a la cirugía para detectar síntomas o riesgo de COVID-19.

- Recomendar en forma estricta y llevar a cabo un control riguroso de medidas de distanciamiento físico y protección de los pacientes las dos semanas previas a la cirugía para disminuir las posibilidades de infección.

- Descartar infección activa por SARS-CoV-2 mediante la realización de una PCR para SARS-CoV-2 mediante hisopado nasofaríngeo lo más cercana posible a la cirugía, lo ideal sería dentro de las 72 horas previas.

- Realizar una segunda evaluación de la clínica y de los antecedentes epidemiológicos en la valoración preoperatoria del anestesiólogo antes de la cirugía para detectar síntomas o riesgo de COVID-19.

\section{En caso de cirugía de urgencia sugerimos:}

- Considerar que todo paciente es posible portador de COVID-19 hasta que no se demuestre lo contrario.

- Ante la imposibilidad de tener un resultado de prueba de PCR para SARS-CoV-2 en forma rápida y expedita, se recomienda realizar tomografía computarizada de tórax en el preoperatorio con el objeto de identificar posibles datos de COVID-19.

- Reservar la indicación del uso sistemático de serología de SARS-CoV-2 (IgG e IgM) a diagnóstico de casos sospechosos en función del contexto clínico.

\section{Para minimizar el riesgo en los profesionales de la salud se recomienda:}

- Considerar que todo paciente es posible portador de COVID-19 hasta que no se demuestre lo contrario.

- Información y actualización continua de profesionales de la salud en relación con la enfermedad y en particular con el uso de equipos de protección personal (EPP).

- Estricto lavado frecuente de manos siguiendo las recomendaciones de la Organización Mundial de la Salud.

- El uso de mascarilla quirúrgica N95 o similares por profesionales.

- El uso de protección adicional (mascarilla FFP2 o superior, bata antisalpicaduras y pantalla o gafas cerradas) en los procedimientos que puedan generar aerosoles.

Correspondencia:

Dr. Juan Roberto Torres Cisneros

E-mail: jrobertotorres@amcg.org.mx 